\title{
Effect of situational, attitudinal and demographic factors on railway vibration annoyance in residential areas
}

\author{
Eulalia Peris, ${ }^{\text {a) }}$ James Woodcock, Gennaro Sica, Calum Sharp, Andrew T. Moorhouse, \\ and David C. Waddington \\ Acoustics Research Centre, University of Salford, Salford, Greater Manchester, M5 4WT, United Kingdom
}

(Received 4 February 2013; revised 12 November 2013; accepted 15 November 2013)

\begin{abstract}
Railway induced vibration is an important source of annoyance among residents living in the vicinity of railways. Annoyance increases with vibration magnitude. However, these correlations between the degree of annoyance and vibration exposure are weak. This suggests that railway vibration induced annoyance is governed by more than just vibration level and therefore other factors may provide information to understand the wide variation in annoyance reactions. Factors coming into play when considering an exposure-response relationship between level of railway vibration and annoyance are presented. The factors investigated were: attitudinal, situational and demographic factors. This was achieved using data from field studies comprised of face-to-face interviews and internal vibration measurements $(\mathrm{N}=755)$. It was found that annoyance scores were strongly influenced by two attitudinal factors: Concern of property damage and expectations about future levels of vibration. Type of residential area and age of the respondent were found to have an important effect on annoyance whereas visibility of the railway and time spent at home showed a significant but small influence. These results indicate that future railway vibration policies and regulations focusing on community impact need to consider additional factors for an optimal assessment of railway effects on residential environments. (c) 2014 Acoustical Society of America. [http://dx.doi.org/10.1121/1.4836495]
\end{abstract}

PACS number(s): 43.40.Ng, 43.50.Qp, 43.50.Sr [LMW]

Pages: 194-204

\section{INTRODUCTION}

Noise annoyance research has shown that a higher noise exposure is responsible for an increase in annoyance (Schultz, 1978; Miedema and Vos, 1998; Miedema and Oudshoorn, 2001). However, the correlations between the acoustic parameters and individual annoyance were found to be weak, and therefore, further investigations were made to examine the influence of non-acoustic factors on annoyance judgments. Furthermore, it has been found that there are large differences in the reported annoyance response between studies for the same noise exposure level, which may partly be explained by non-acoustical differences (Fidell et al., 2011; Schomer et al., 2012). Several attitudinal, situational, and demographic factors as co-determinants of noise annoyance have been investigated by several authors, and it is relevant to review these before considering comparable responses to vibration annoyance.

Past investigations have shown that attitudinal variables such as self-reported noise sensitivity and fear due to the source have a large influence on people's overall noise annoyance reactions. Self-reported noise sensitivity has been shown to be one of the most important non-acoustical factors that influence noise exposure-response relationships (Fields, 1993; Miedema and Vos, 1999; Guski, 1999; Job, 1999). Noise sensitivity is related to psychological attitudes such as nervousness and introversion (Moch-Sibony, 1980), and studies indicate that this relationship probably also has a genetic

\footnotetext{
a) Author to whom correspondence should be addressed. E-mail: e.peris@salford.ac.uk
}

component (Heinonen-Guzejev, 2008). Miedema and Vos (1999) quantified the size of the impact that noise has on annoyance to be equal to that of being exposed to an additional $11 \mathrm{~dB}$ change in the noise exposure. Overall fear of the source is another attitudinal factor that was found to have a large impact on noise annoyance from transportation sources (Fields and Walker, 1982; Job, 1988; Fields, 1993; Miedema and Vos, 1999). People who experienced fear related to the noise source were likely to report higher annoyance than people who did not experience such fear. Miedema and Vos (1999) estimated that fear of the noise source had an impact on annoyance equivalent to a $19 \mathrm{~dB}$ increase in the noise exposure. However, for railway traffic, the effect of fear was found to be very low. This may have been due to low variance among responses because fewer people tend to fear railway transportation. People's expectations about sound levels and its relationship to the overall noise annoyance were not investigated in detail. Some noise annoyance studies suggest that annoyance may increase if the residents expect noise from the transportation source to increase (Hatfield and Job, 1998: Guski, 1999; Guski, 2001). However, there have previously been no conclusive data on this topic.

The perception of the neighborhood and the global environment were also shown to have a link with the annoyance induced by the noise source. Annoyance increases if the characteristics of the neighborhood are perceived and believed to be negative (Fields and Walker, 1982; Job 1988; Vallet, 1996). Other aspects related to the presence of the noise source (smells, dust, dirt, light) also influence the annoyance response (Nelson, 1987; Vallet, 1996; Klæboe et al., 1998). 
Many situational variables were found to increase the likelihood of reporting noise annoyance. For an exposure of equal noise level, noise annoyance was shown to be greater in towns than in rural surroundings (Cohen, 1978; Bradley and Jonah, 1979; Vallet, 1996). Lercher and Kofler (1996) showed high annoyance in rural areas compared to urban areas and argued that this may be due to people's expectations on background noise levels. Moreover, the background noise levels of the surroundings were found to influence the response (Klæboe et al., 2006). On the other hand, Fields (1998) concluded that reactions to an environmental noise source are affected very little by the ambient noise. Another important situational variable was the visibility of the noise source. Reported visibility was shown to increase annoyance responses (Bangjun et al., 2003). Moreover, both objective and subjective visibility have been found to influence strongly noise annoyance from wind turbines (Pedersen and Larsman, 2008). Time spent at home has been suggested to be of influence to noise annoyance (Nivison and Endresen, 1993; Paunovic et al., 2009). The greater the time spent at home the greater the degree of exposure and therefore the greater the annoyance.

Though results differ slightly, in general, sociodemographic factors have been shown to have little influence on annoyance (Fields, 1993; Miedema and Vos, 1999). Recently, age has been found to have a significant influence in these relationships with the largest proportion of respondents expressing high annoyance is in the middle age ranges (Van Gerven et al., 2009). Home ownership was evident as a possible factor although conclusions could not be drawn. According to Miedema and Vos (1999), the annoyance felt is greater for the owner of a home exposed to noise than for a renter, although this effect seems to be quite small.

After noise, vibration is one of the most widely experienced problems associated with railways (Fields, 1979) in residential areas. Annoyance due to railway vibration may arise during the pass-by of a train, when mechanical vibrations generated at the wheel-rail contact are transferred from the track to the soil and into the foundations of the dwelling, exciting floors, and walls (Stiebel, 2011). Similar to noise annoyance, the percentage of people annoyed by transportation vibration increases with vibration magnitude (Öhrström and Skånberg, 1996; Klæboe and Fyhri, 1999; Zapfe et al., 2009; Woodcock et al., 2011). Not only the vibration magnitude has shown an effect on people's responses to environmental vibration but also the frequency of occurrence, duration of the vibration event, and accompanying noise (Yonekawa, 1977; Obermeyer, 1983; Howarth, 1989). The correlations found between vibration levels and annoyance are weak. In field studies, noise exposure has been found to account for between $4 \%$ and $20 \%$ of the variance in annoyance on the individual level (Brink and Wunderli, 2010; Fields, 1993; Job, 1988). The study "Human Response to Vibration in Residential Environments" by the University of Salford (Woodcock et al., 2011) showed that the Spearman's correlation coefficient between commonly used measures of vibration and annoyance range between 0.12 and 0.17 . If these values were to be converted to $\mathrm{R}^{2}$ values on the individual level, this would equate to $1 \%-4 \%$ explained variance for railway induced vibration indicating that vibration annoyance reactions, even more so than noise annoyance, are governed by other than acoustic or vibrational parameters. For example, Fields (1979) suggested that people are more likely to react to vibration if they believe that there is danger from the railway. He found that under some circumstances people's concern was closely related to their annoyance reactions.

However, investigations on factors influencing vibration exposure-response are almost nonexistent, and therefore, there is no evidence yet from the literature that annoyance reactions due to transport vibration in residential environments are different from those that influence relations between noise and annoyance.

In this paper, relationships between vibration annoyance and vibration exposure in residential environments from mixed railway sources featuring several situational, attitudinal, and demographic factors are assessed using ordinal logit regression analyses. The results presented in this paper are intended to help local authorities, architects, urban planners, consultants, and environmental practitioners to be better able to control annoyance due to railway vibration. The specific objectives of the study are discussed in the next section.

\section{OBJECTIVES}

This paper aims to provide new information about situational (e.g., type of residential area, visibility of the source and hours spent at home), demographic (e.g., age, gender) and attitudinal factors (e.g., self reported sensitivity to vibration, concern of property damage and expectations) leading to annoyance due to railway vibration. To improve the environment of residents living in the vicinity of railways, additional non-vibrational factors should be considered when looking into the relation between exposure and response. A broader picture of each situation could be studied to predict individual responses, therefore, the objectives of this paper are as follows: (1) to gain an understanding of and to explore the influence of situational, attitudinal, and demographic characteristics on annoyance response to railway vibration; (2) to investigate which variables, if any, mediate or moderate the effect of railway vibration on annoyance; (3) to derive exposure-response relationships for railway vibration featuring different situational, attitudinal, and demographic characteristics; and (4) to identify whether there are variables that are specifically important or more important for vibration reactions than for noise reactions.

\section{METHODS}

\section{A. Study design and sample}

The data in this paper consist of vibration measurements and responses from railway and were collected in the UK, more specifically in the North-West and the Midlands areas during 2009 and 2010 as part of the study "Human Response to Vibration in Residential Environments" by the University of Salford (Waddington et al., 2014).

The study sites were chosen to provide an overall representative and robust sample size, as well as to maximize the 
range of exposures to vibration and maximize the potential number of respondents. This was achieved by selecting sites that are within a range of distances from the railway track, that are exposed to different kinds of railway traffic, and that contain different kinds of properties. The sites were identified according to their population density and distance from the vibration source. Properties within a distance of $100 \mathrm{~m}$ from the railway were targeted to ensure a relatively high and perceptible vibration level for the respondents.

Face to face questionnaires were used with associated high-quality vibration data being obtained internally within respondent's properties. A total of 931 questionnaires were collected, estimates of vibration exposure being available for 755 of these. Therefore, 755 case studies were available for the analyses presented in this paper.

\section{B. Vibration exposure}

The measurement of vibration was carried out using Guralp CMG-5TD force-feedback strong-motion accelerometers and the measurement protocol employed in the field consisted of a long term vibration monitoring at an external position (generally a garage or a shed) along with time synchronized short-term internal snapshot measurements. Vibration was measured in the floor, in the room in which the respondent stated they could feel the highest magnitude of vibration. By determining the velocity ratio between the control and the internal measurements, an estimation of 24-h internal vibration exposure was obtained.

For each respondent, the frequency-weighted rootmean-square acceleration values (using the $\mathrm{W}_{\mathrm{k}}$ weighting curve, which applies to vertical vibration and demonstrates maximum sensitivity to vertical acceleration in the frequency range $4-12.5 \mathrm{~Hz}$ ) in accordance with International Organization for Standardization (1997) were calculated over all railway vibration events identified in a $24 \mathrm{~h}$ period.

In terms of characteristics of the vibration data collected in the survey, the range of exposures measured in rms $W_{k}$ for $24 \mathrm{~h}$ goes from $0.0001 \mathrm{~m} / \mathrm{s}^{2}$ to $0.0374 \mathrm{~m} / \mathrm{s}^{2}$, the mean being $0.0041 \mathrm{~m} / \mathrm{s}^{2}$. The weighted vertical peak levels measured in the study go from $0.0008 \mathrm{~m} / \mathrm{s}^{2}$ to $0.31 \mathrm{~m} / \mathrm{s}^{2}, 0.036 \mathrm{~m} / \mathrm{s}^{2}$ being the mean; thus the vibration data used for the analysis includes a wide range of vibration exposures, most of which are easily perceptible regarding to International Organization for Standardization (1997).

\section{Questionnaire}

To measure the "response" component, a social survey questionnaire was used to collect data from the respondents (Condie et al., 2009). The questionnaire was introduced as a survey of neighborhood satisfaction and is divided into different sections.

Within the vibration questions, respondents self-assessed their degree of overall annoyance using a five-point semantic scale, as recommended by the standard International Organization for Standardization (2003a) and through the following question: "Thinking about the last 12 months or so, when indoors at home, how bothered, annoyed, or disturbed have you been by feeling vibration or hearing or seeing things rattle, vibrate, or shake caused by the railway, including passenger trains, freight trains, track maintenance or any other activity form the railway, would you say not at all, slightly, moderately, very, or extremely?"

The respondents who stated they could not feel vibration were recoded to the lowest category of the five-point semantic annoyance scale. The annoyance response categories were converted to a scale ranging from 0 to 100 and centered to the midpoints of these categories by the procedure described in Miedema and Oudshoorn (2001). This conversion is based on the assumption that a scale with a fixed number of categories, irrespective of wording nuances and the specific labeling of the response categories, will nevertheless divide the range from 0 to 100 in equally spaced intervals. This conversion was made in order to compare and unify any analyses on the questionnaire as it was very large and other items of the questionnaire used different scales. Exposure-response relationships are generally analyzed for the percentage of highly annoyed people (\%HA), which in accordance to the ICBEN recommendations (Fields et al., 2001) are the "very" or "extremely" categories in the fivepoint semantic scale.

Several factors that could potentially influence the response to vibration were addressed by the social survey questionnaire. The questionnaire collected specific questions on demographics, attitudes, and situations. The variables included in the analysis presented in this paper were asked and measured as indicated below.

Sensitivity to vibration: this was measured on a fivepoint semantic scale ranging from "not at all" to "extremely" and through the following question: "How sensitive would you say you are personally to vibration in general? Would you say you are not at all sensitive, slightly sensitive, moderately sensitive, very sensitive, or extremely sensitive?"

Concern of property damage: this was measured on a five-point semantic scale ranging from "not at all" to "extremely" and through the following question: "We would like to know if you are concerned that the vibration may damage this home or your possessions inside it in any way. Are you not at all concerned, slightly concerned, moderately concerned, very concerned, or extremely concerned?"

Respondents' expectation: this was assessed using a three-point categorical scale (better, same, worse) and through the following question "In the future, do you think the level of vibration you experience while indoors at home will get worse, get better or remain the same?" The responses were dichotomized into individuals who reported expecting worse levels versus those expecting levels to get better or remain the same.

Type of residential area: this was assessed using a categorical scale (Centre of a large city, suburbs/outskirts of a large city, large town or small city, small town, village, countryside) and through the following question: "In which of the following is the property situated?" The responses were dichotomized into individuals residing in a small town, village, or countryside versus those living in a city, suburbs of a large city, or a large town.

Visibility of the railway: this was assessed by a Yes/No question formulated in the following way: "From any room 
in this home, can you see a railway track or any type of passing train."

Time spent at home: the residents were asked to specify during which $3 \mathrm{~h}$ time interval they were likely to be at home in a set of Yes/No questions of the type: "During a typical weekday, that is, Monday to Friday, what times are you usually at home? Are you at home between..."

Ownership: this was assessed using a categorical scale and through the following question: "Do you or your family: Own outright or with a mortgage, part-rent and part-own with a mortgage, rent from a private landlord/letting agency, or rent from a housing association or council?" The responses were dichotomized into individuals who owned the property versus those who rented the property.

Age and gender: age was recorded with open questions as follows: "Do you mind me asking how old you are?" The gender of the respondent was recorded by the interviewer.

\section{Statistical analyses}

The social survey data were archived and analyzed with SPSS v. 17 (SPSS Inc., Chicago). To examine the relationships between annoyance scores and vibration exposure featuring modifying factors, ordinal logit models (Klæboe et al., 2003) were used to generate parameter estimates for the annoyance thresholds (not at all, slightly, moderately, very, and extremely). Equation (1) was used to obtain the estimated exposure-response relationships from the estimated parameters. The equation indicates the probability of obtaining vibration annoyance response higher or equal to $j$

$$
\begin{gathered}
P\left(Y \geq j \mid \mathbf{X}_{i}=\mathbf{x}_{i}\right)=1-\left(\left(e^{\hat{\tau}_{j}-\hat{\beta}^{\prime} \mathbf{x}_{i}}\right) /\left(1+e^{\hat{\tau}_{j}-\hat{\beta}^{\prime} \mathbf{x}_{i}}\right)\right) \\
j \in[1, \ldots, J-1],
\end{gathered}
$$

where $\hat{\tau}_{j}$ indicates the $j$ th estimated threshold, and $\hat{\beta}$ is a vector of the estimated parameters for the exposure value and modifying factors. There are $J$ annoyance categories. $\mathrm{X}_{i}$ is a vector of exposures and modifying factors for an individual $i$.

Figure 1 shows the threshold concept for the ordinal response with five categories. It describes the logistic probability distribution of people being annoyed to a degree $j$. The graph is plotted using the regression and cut-point values estimated from the data collected.

Results are presented considering only two independent variables entered as additive effects: Exposure and one factor. There was no significant correlation between the two explanatory variables except for the case of concern of property damage and exposure which showed a small positive significant correlation of $0.127 * * *$. As a result, the influence of concern of property damage was further investigated using mediation analysis. Collinearity was tested by running a linear regression analysis using a collinearity diagnostic Variance Inflation Factor (VIF) and tolerance (Field, 2009). The values observed were smaller than 1 for the VIF and greater than 1 for the tolerance except for concern of property damage and exposure $(\mathrm{VIF}=1.01$; Tolerance $=0.98)$. Variance proportions were also examined and showed independency between these variables. For all the models, the

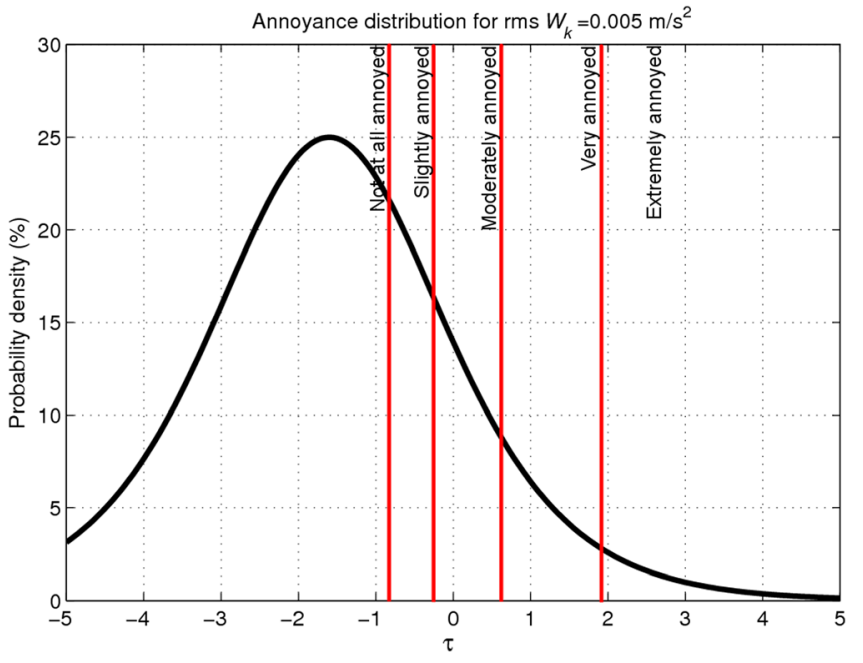

FIG. 1. (Color online) Threshold concept for ordinal logistic regression with five annoyance categories and a given vibration level. The graph shows the probability distribution of the fitted ordinal logit regression with the estimated cut-points $(\tau)$. The probability of being annoyed to degree $j$ is given by the areas between the $J-1$ cut points for a given vibration level.

first variable entered was exposure and then the factor to be tested.

Mediation and moderation effects were tested through an analytical procedure as described in Baron and Kenny (1986). Only concern of property damage showed a mediating effect; therefore, all the other factors are presented as main effects. Concern of property damage is also treated as a dependent variable and represented against exposure in the results section.

\section{RESULTS}

\section{A. Sensitivity to vibration}

The social survey questionnaire asked respondents to quantify on a five-point semantic scale the extent to which they felt they were sensitive to vibration (categories were transformed into a scale ranging from 0 to 100). Selfreported sensitivity to vibration was included in the ordinal logistic analysis as an independent variable along with the vibration exposure. However, the inclusion of sensitivity as additional independent variable in the model only featuring exposure did not show a significant improvement of the model fit.

\section{B. Concern of property damage}

The social survey questionnaire asked respondents to quantify on a five-point semantic scale the extent to which they felt concerned that vibration due to railway activity was causing damage to their property (categories were transformed into a scale ranging from 0 to 100). Association between concern of property damage and vibration exposure was found; thus, causal pathways between vibration exposure, annoyance, and concern of property damage were explored. Table I shows the results from the ordinal logit model parameter estimation between concern of property damage and vibration exposure. 
The relationship for concern of damage to property and vibration exposure is presented in Fig. 2. It can be seen that as vibration exposure increases, the proportion of respondents expressing concern of damage to their property was found to increase.

Figure 3 shows the proportion of people reporting high annoyance for a given level of self-reported concern of property damage. Here, as part of the exploration of possible causal pathways, the concern of property damage is viewed as independent variable predicting annoyance. This figure suggests that concern of property damage has a large impact on self-reported annoyance, showing that people concerned were more annoyed than people without such feeling. The high association encountered between annoyance and concern could mean that these two variables are in part measuring the same reaction.

Because of the effect of exposure on concern showed in Fig. 2 and the effect of concern on high annoyance showed in Fig. 3, we can see that there is an association between exposure, concern of property damage, and annoyance. That may mean concern of property damage mediates the relationship. A causal model where the effect of vibration exposure on annoyance from railway vibration is mediated by concern of property damage was tested to provide an understanding of the working mechanism between concern of property damage, vibration exposure, and self-reported annoyance. Figure 4 shows a representation of the mediation effects of the concern of damage attitude on vibration exposure and annoyance. The numbers in Fig. 4 represent the correlation coefficients. After adding concern of property damage, the effect of vibration exposure appears to be smaller ( 0.115 without concern; 0.042 with concern). Thus, concern of property damage partially mediates the effect of vibration exposure on self-reported vibration annoyance. The Sobel test (Sobel, 1986) was used to determine whether there was significant partial mediation. The Sobel test $p$-value was less than 0.05 and therefore indicates that concern of property damage is a statistically significant mediator of the effect of vibration exposure on self -reported vibration annoyance. However, it is not a complete mediation, suggesting that even if concern of property damage was one meditational pathway, it is certainly not the only one.

TABLE I. Results of the estimation of ordinal logit model for the degree of concern of property damage from railway vibration as a function of vibration exposure.

\begin{tabular}{|c|c|c|c|c|}
\hline \multirow[b]{3}{*}{ Parameter Estimates } & \multicolumn{4}{|c|}{ Estimates } \\
\hline & \multirow[b]{2}{*}{ Estimates } & \multirow[b]{2}{*}{ SE } & \multicolumn{2}{|c|}{$95 \%$ CI } \\
\hline & & & Lower & Upper \\
\hline \multicolumn{5}{|l|}{ Threshold $(\hat{\tau})$} \\
\hline Slightly Concerned & -0.475 & 0.557 & -1.566 & 0.616 \\
\hline Concerned & 0.343 & 0.563 & -0.760 & 1.446 \\
\hline Highly Concerned & $1.869^{* *}$ & 0.615 & 0.663 & 3.075 \\
\hline \multicolumn{5}{|l|}{ Location $(\hat{\beta})$} \\
\hline $\log _{10} \mathrm{rms} W_{k}$ & $0.908^{* * * *}$ & 0.222 & 0.473 & 1.342 \\
\hline
\end{tabular}

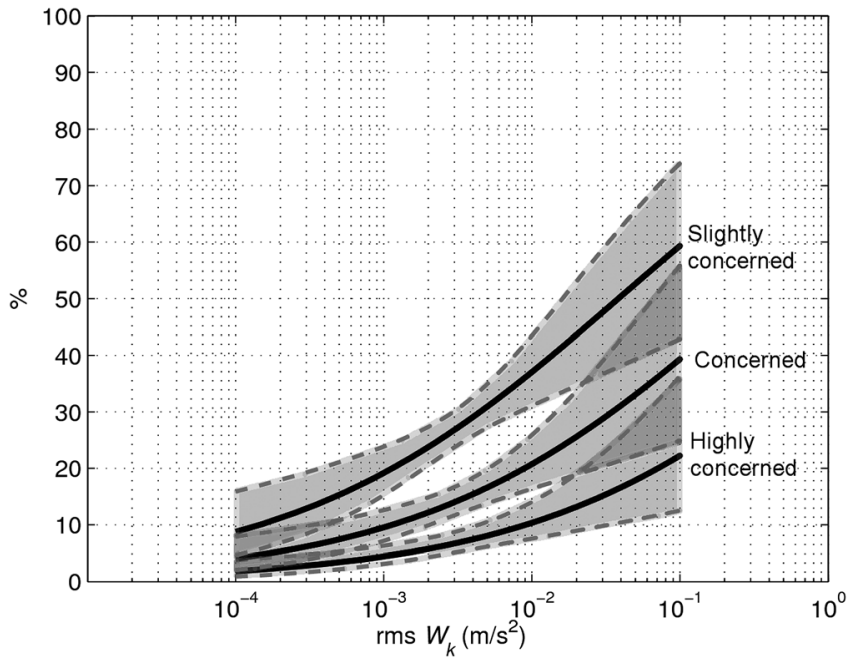

FIG. 2. Exposure-response curves showing the proportion of people reporting being highly concerned, concerned and slightly concerned for property damage due to railway vibration, for a given vibration exposure. The gray bands indicate the $95 \% \mathrm{CI}$.

\section{Expectation}

Expectation was included in the ordinal logit analysis as an independent variable along with the vibration exposure. The inclusion of this variable resulted in a significant $(p<0.001)$ improvement relative to the exposure only model.

Table II shows the results from the ordinal logit model parameter estimation. These results are used to calculate the estimated exposure-response relationship when expectation is set to worse and better/same. Figure 5 shows the exposure-response relationship for people expecting the vibration levels to get worse and for people expecting the vibration levels to remain the same or get better. The curves indicate the percentage of respondents expected to be highly annoyed (\%HA) by a given vibration exposure from the railway. Figure 5 indicates that at the same exposure level of $0.01 \mathrm{~m} / \mathrm{s}^{2}$, four times this proportion were found to be highly annoyed for people believing levels of vibration will get

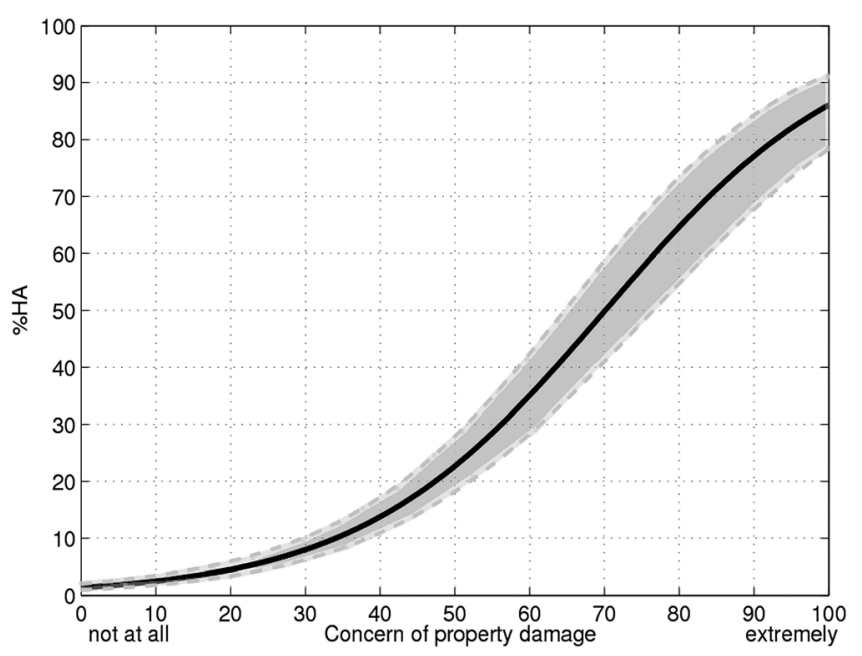

FIG. 3. Relationship showing the percentage of people highly annoyed $(\% \mathrm{HA})$ for a given level of self-reported concern of property damage (0 not at all to 100 extremely). The gray bands indicate the $95 \% \mathrm{CI}$. 


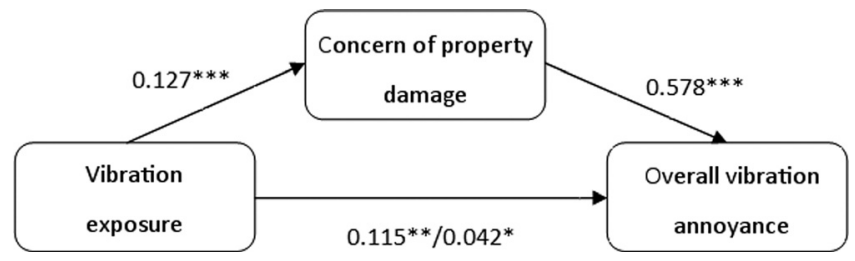

FIG. 4. A schematic overview of the mediation model between concern of property damage, vibration annoyance and vibration exposure. The numbers represent the correlation coefficients $* p<0.1, * * p<0.01, * * * p<0.001$ of the direct and indirect pathways.

worse, whereas $7 \%$ of people believing levels of vibration will remain the same or get better were found to be highly annoyed. These findings suggest that people's expectations regarding changes in the vibration levels strongly influence their annoyance response and that expectations residents have with regard to future exposure have a major influence on top of the vibration exposure levels.

\section{Type of residential area}

Type of residential area was included in the ordinal logit analysis as an independent variable along with the vibration exposure. The inclusion of this variable resulted in a significant $(p<0.001)$ improvement compared to the exposureonly model.

Table III shows the results from the ordinal logit model parameter estimation. These results are used to calculate the estimated exposure-response relationship when the location is fixed to large town/city and small town/village. Figure 6 shows the exposure-response relationship for people living in a city/large town and a small town/village. The curves indicate the percentage of respondents expected to be highly annoyed (\% $\mathrm{HA}$ ) by a given vibration exposure from the railway. Figure 6 indicates that with the same vibration exposure of $0.01 \mathrm{~m} / \mathrm{s}^{2}$, more than twice as many people were found to be highly annoyed by vibration from railway in rural areas such as small towns or villages than in an urban area.

\section{E. Visibility of the railway}

The impact of the visibility of the railway on vibration annoyance was investigated. Visibility was included in the

TABLE II. Results of the estimation of ordinal logit model for the proportion of highly annoyed people (\%HA) from railway vibration as a function of vibration exposure and people's vibration expectations.

\begin{tabular}{|c|c|c|c|c|c|}
\hline \multirow[b]{3}{*}{ Parameter Estimates } & \multicolumn{5}{|c|}{ Estimates } \\
\hline & \multirow[b]{2}{*}{ Estimates } & \multirow[b]{2}{*}{ SE } & \multicolumn{2}{|c|}{$95 \%$ CI } & \multirow[b]{2}{*}{$\operatorname{Exp}(b)$} \\
\hline & & & Lower & Upper & \\
\hline \multicolumn{6}{|l|}{ Threshold $(\hat{\tau})$} \\
\hline Highly Annoyed & $1.629^{* * *}$ & 0.570 & 0.511 & 2.746 & - \\
\hline \multicolumn{6}{|l|}{ Location $(\hat{\beta})$} \\
\hline $\log _{10} \mathrm{rms} W_{k}$ & $0.425^{*}$ & 0.221 & -0.008 & 0.857 & - \\
\hline $\begin{array}{l}\text { Expectation (vibration } \\
\text { will get worse) }\end{array}$ & $1.475^{* * *}$ & 0.186 & 1.111 & 1.839 & 4.371 \\
\hline
\end{tabular}

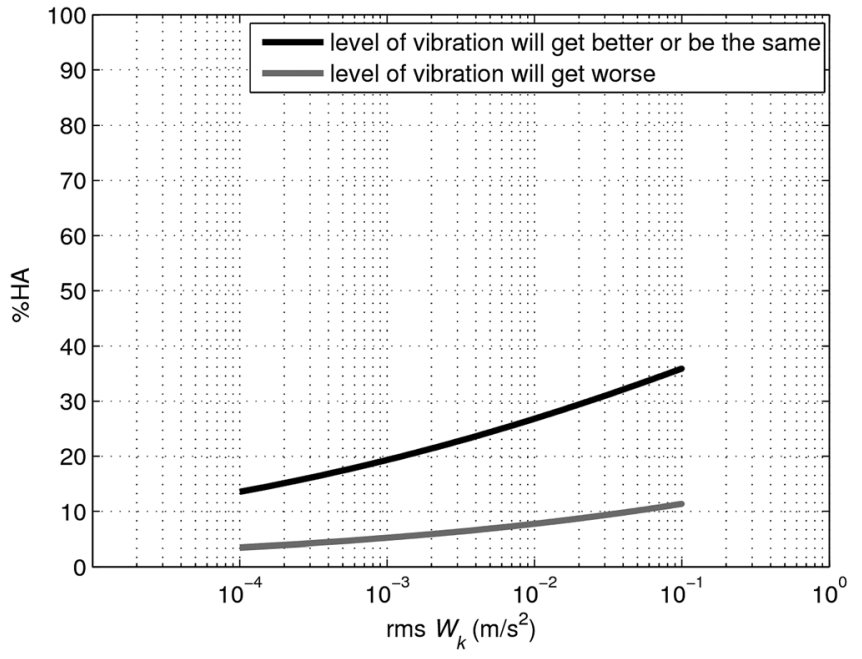

FIG. 5. Exposure-response relationship showing the proportion of people highly annoyed (\%HA) for a given vibration exposure and controlling for expectation.

ordinal logit analysis as a dichotomous independent variable along with the vibration exposure. The inclusion of this variable resulted in a significant improvement compared with the exposure-only model $(p<0.001)$.

Table IV shows the results from the ordinal logit model parameter estimation. These results were used to calculate the estimated exposure-response relationship controlling for visibility of the railway. More people were found to be highly annoyed by vibration from railways in residential environments where the railway is visible than in residential environments where the railway is not visible. Looking at the odds ratio, at the same vibration exposure level, more than 1.6 times as many people were found to be highly annoyed by vibration from railway if the railway was visible compared to dwellings where the railway was not visible.

\section{F. Time spent at home}

The impact of the hours spent at home on vibration annoyance was investigated. The inclusion of this variable resulted in a significant $(p<0.001)$ improvement over the exposure-only model. Table $\mathrm{V}$ shows the results from the

TABLE III. Results of the estimation of ordinal logit model for the proportion of highly annoyed people (\%HA) from railway vibration as a function of vibration exposure and type of residential area.

\begin{tabular}{|c|c|c|c|c|c|}
\hline \multirow[b]{3}{*}{ Parameter Estimates } & \multicolumn{5}{|c|}{ Estimates } \\
\hline & \multirow[b]{2}{*}{ Estimates } & \multirow[b]{2}{*}{ SE } & \multicolumn{2}{|c|}{$95 \% \mathrm{CI}$} & \multirow[b]{2}{*}{$\operatorname{Exp}(b)$} \\
\hline & & & Lower & Upper & \\
\hline \multicolumn{6}{|l|}{ Threshold $(\hat{\tau})$} \\
\hline Highly Annoyed & $1.264^{*}$ & 0.564 & 0.158 & 2.370 & - \\
\hline \multicolumn{6}{|l|}{ Location $(\hat{\beta})$} \\
\hline $\log _{10} \mathrm{rms} W_{k}$ & $0.628^{* *}$ & 0.217 & 0.203 & 1.054 & - \\
\hline $\begin{array}{l}\text { Type of residential area } \\
\text { (small town/village/ } \\
\text { countryside) }\end{array}$ & $0.915^{* * *}$ & 0.159 & 0.604 & 1.227 & 2.497 \\
\hline
\end{tabular}




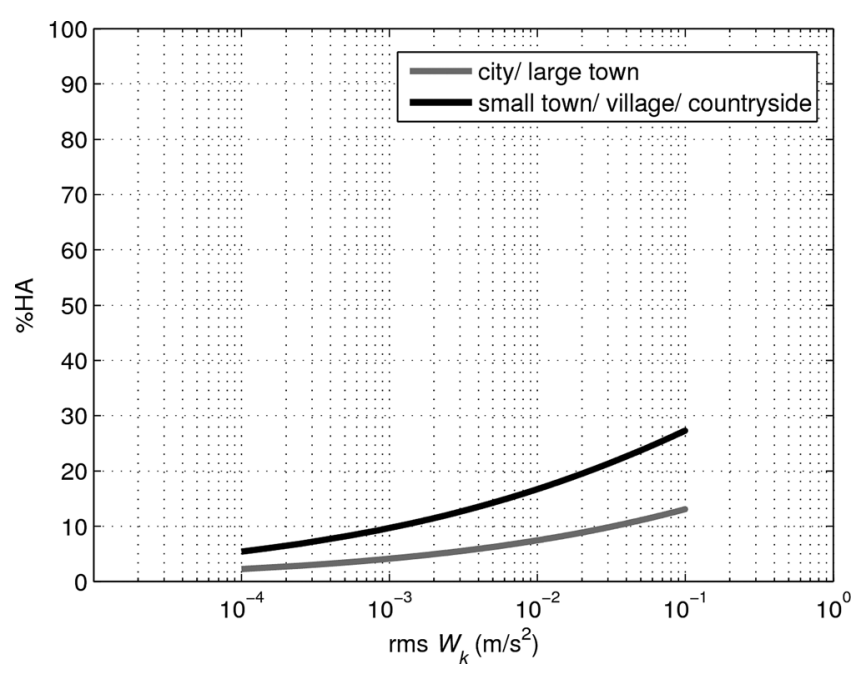

FIG. 6. Exposure-response relationship showing the proportion of people highly annoyed (\%HA) for a given vibration exposure and controlling for type of location.

ordinal logit model parameter estimation. These results were used to calculate the estimated exposure-response relationship controlling for hours spent at home. Time spent at home showed a significant but small influence on reported annoyance. At the same vibration exposure level, people in residential environments who spend less than $10 \mathrm{~h}$ at home during a week day are more likely to be highly annoyed than people who spend more than $16 \mathrm{~h}$ at home during a week day. At the same vibration exposure, the odds ratio shows that 2.2 times more people are expected to be highly annoyed by vibration from the railway if they spend less than $10 \mathrm{~h}$ at home than if they spend more than $10 \mathrm{~h}$ at home.

\section{G. Ownership}

Vibration annoyance was found not to be correlated significantly with ownership. Concern of property damage, which is more likely when the property is owned than when it is rented, did not moderate the relationship between ownership and annoyance (i.e., for different levels of concern of property damage, the relationship between annoyance and ownership did not change). However, ownership proved to be related to concern of property damage, which was shown earlier (cf. Sec. IV B) to be correlated significantly with

TABLE IV. Results of the estimation of ordinal logit model for the proportion of highly annoyed people $(\% \mathrm{HA})$ from railway vibration as a function of vibration exposure and visibility of the railway.

\begin{tabular}{|c|c|c|c|c|c|}
\hline \multirow[b]{3}{*}{ Parameter Estimates } & \multicolumn{5}{|c|}{ Estimates } \\
\hline & \multirow[b]{2}{*}{ Estimates } & \multirow[b]{2}{*}{ SE } & \multicolumn{2}{|c|}{$95 \% \mathrm{CI}$} & \multirow[b]{2}{*}{$\operatorname{Exp}(b)$} \\
\hline & & & Lower & Upper & \\
\hline \multicolumn{6}{|l|}{ Threshold $(\hat{\tau})$} \\
\hline Highly Annoyed & 0.684 & 0.540 & -0.374 & 1.741 & - \\
\hline \multicolumn{6}{|l|}{ Location $(\hat{\beta})$} \\
\hline $\log _{10} \mathrm{rms} W_{k}$ & $0.634^{* *}$ & 0.212 & 0.217 & 1.050 & - \\
\hline Visibility (railway no visible) & $-0.472^{* * *}$ & 0.190 & -0.845 & -0.099 & 1.603 \\
\hline
\end{tabular}

annoyance. Table VI shows the results from the ordinal logit model parameter estimation with ownership and exposure as predictors of concern of property damage. It is seen that for a given magnitude of vibration exposure, the proportion of highly concerned people is 1.622 times higher for owners than for renters.

\section{H. Age and gender}

The effects of age in annoyance reactions due to railway vibration were investigated to see whether annoyance from railway vibrations varies as a function of age. Age was entered in the analyses as a curvilinear effect following previous investigations on community noise annoyance (Van Gerven et al., 2009). First, to justify the addition of $\mathrm{Age}^{2}$ in the ordinal logistic regression model, the quadratic effect was tested using a hierarchical multiple regression approach. The inclusion of this non-linear addition to the regression model was statistically significant, and the final model using $\mathrm{Age}^{2}$ proved to add incremental predictive capacity to the linear model.

Table VII shows the results from the ordinal logit model parameter estimates. These results were used to calculate the estimated exposure-response relationship curves controlling for age. Age and the square of age were included as independent variables in the vibration exposure-response model. The inclusion of this variable resulted in a significant improvement from the exposure-only model fit $p<0.001$. Figure 8 shows the predicted $\% \mathrm{HA}$ as a function of vibration exposure level. Curves are presented for three selected ages 20,45 , and 80 . It can be seen from Fig. 7 that at a given vibration exposure level, self-reported annoyance was found to be highest in people of 45 years old, lowest in people of 80 years old and intermediate in people of 20 years old. That suggests an inverted U-shaped relationship between age and annoyance (the annoyance is higher for people in the middle range). It shows the same pattern encountered in noise studies.

Gender showed no influence on vibration annoyance reporting. The inclusion of this variable on the ordinal logit model did not significantly improve the exposure-only

TABLE V. Results of the estimation of ordinal logit model for the proportion of highly annoyed people (\%HA) from railway vibration as a function of vibration exposure and time spent at home.

\begin{tabular}{|c|c|c|c|c|c|}
\hline \multirow[b]{3}{*}{ Parameter Estimates } & \multicolumn{5}{|c|}{ Estimates } \\
\hline & \multirow[b]{2}{*}{ Estimates } & \multirow[b]{2}{*}{ SE } & \multicolumn{2}{|c|}{$95 \% \mathrm{CI}$} & \multirow[b]{2}{*}{$\operatorname{Exp}(b)$} \\
\hline & & & Lower & Upper & \\
\hline \multicolumn{6}{|l|}{ Threshold $(\hat{\tau})$} \\
\hline Highly Annoyed & $0.696^{*}$ & 0.557 & -0.395 & 1.787 & - \\
\hline \multicolumn{6}{|l|}{ Location $(\hat{\beta})$} \\
\hline $\log _{10} \mathrm{rms} W_{k}$ & $0.736^{* *}$ & 0.215 & 0.314 & 1.158 & - \\
\hline $\begin{array}{l}\text { Less than } 10 \text { hours at home } \\
\text { (more than } 16 \text { hours at home) }\end{array}$ & $0.815^{* * *}$ & 0.402 & 0.027 & 1.603 & 2.259 \\
\hline $\begin{array}{l}\text { Between } 10 \text { and } 16 \text { hours at } \\
\text { home (more than } 16 \text { hours } \\
\text { at home) }\end{array}$ & $0.282^{*}$ & 0.171 & -0.052 & 0.617 & 1.326 \\
\hline
\end{tabular}


TABLE VI. Results of the estimation of ordinal logit model for the proportion of highly concerned of property damage $(\% \mathrm{HC})$ from railway vibration as a function of vibration exposure and ownership.

\begin{tabular}{|c|c|c|c|c|c|}
\hline \multirow[b]{3}{*}{ Parameter Estimates } & \multicolumn{5}{|c|}{ Estimates } \\
\hline & \multirow[b]{2}{*}{ Estimates } & \multirow[b]{2}{*}{ SE } & \multicolumn{2}{|c|}{$95 \% \mathrm{CI}$} & \multirow[b]{2}{*}{$\operatorname{Exp}(b)$} \\
\hline & & & Lower & Upper & \\
\hline \multicolumn{6}{|l|}{ Threshold $(\hat{\tau})$} \\
\hline Highly Concerned & 0.273 & 0.569 & -0.842 & 1.388 & - \\
\hline \multicolumn{6}{|l|}{ Location $(\hat{\beta})$} \\
\hline $\log _{10} \mathrm{rms} W_{k}$ & $0.901^{* * *}$ & 0.224 & 0.463 & 1.340 & - \\
\hline Ownership (rent) & $-0.484^{*}$ & 0.220 & -0.916 & -0.051 & 1.622 \\
\hline
\end{tabular}

${ }^{*} p<0.1 ;{ }^{* *} p<0.01 ;{ }^{* * *} p<0.001 ; \mathrm{N}=754$.

model. These results indicate that men and women react similarly in terms of annoyance to vibration from railway in residential environments.

\section{DISCUSSION}

Exposure-response relationships were shown as a function of exposure and attitudinal, situational, and demographic factors using ordinal logit regression. Vibration annoyance was shown to be dependent on some of these factors in addition to a measure of vibration exposure. Concern of property damage and expectations of future vibration levels constituted the most important annoyance parameters. Investigations into people's reactions to noise have already shown the importance of attitudinal factors such as selfreported sensitivity to noise and fear of the noise source (Fields, 1993; Miedema and Vos, 1999). Those factors were shown to have an impact equal to an $11 \mathrm{~dB}$ and $19 \mathrm{~dB}$ change in noise exposure, respectively. Therefore, the results of this paper suggest that while attitudinal factors are of great importance for both noise and vibration annoyance, attitudinal factors influencing noise reactions have to be distinguished from the ones influencing vibration reactions. Furthermore, the impact on vibration annoyance due to these attitudinal factors was found to be larger than those encountered for noise annoyance.

Self-reported sensitivity to vibration did not show a significant improvement of the exposure-only model fit.

TABLE VII. Results of the estimation of ordinal logit model for the proportion of highly annoyed people $(\% \mathrm{HA})$ from railway vibration as a function of vibration exposure and age.

\begin{tabular}{lccrr}
\hline \hline & \multicolumn{4}{c}{ Estimates } \\
\cline { 2 - 5 } & & & \multicolumn{2}{c}{$95 \%$ CI } \\
\cline { 3 - 5 } Parameter Estimates & Estimates & SE & Lower & Upper \\
\hline Threshold $(\hat{\tau})$ & & & 0.858 & 4.008 \\
Highly Annoyed & $2.433^{* *}$ & 0.804 & & \\
Location $(\hat{\beta})$ & & & 0.277 & 1.100 \\
Log $_{10}$ rms $W_{k}$ & $0.698^{* *}$ & 0.210 & -14.037 & -3.962 \\
$(\text { Age } / 100)^{2}$ & $-9.000^{* * *}$ & 2.570 & 3.504 & 13.659 \\
Age $/ 100$ & $8.582^{* *}$ & 2.590 & & \\
\hline \hline
\end{tabular}

${ }^{*} p<0.1 ;{ }^{* *} p<0.01 ;{ }^{* * * *} p<0.001 ; \mathrm{N}=755$.

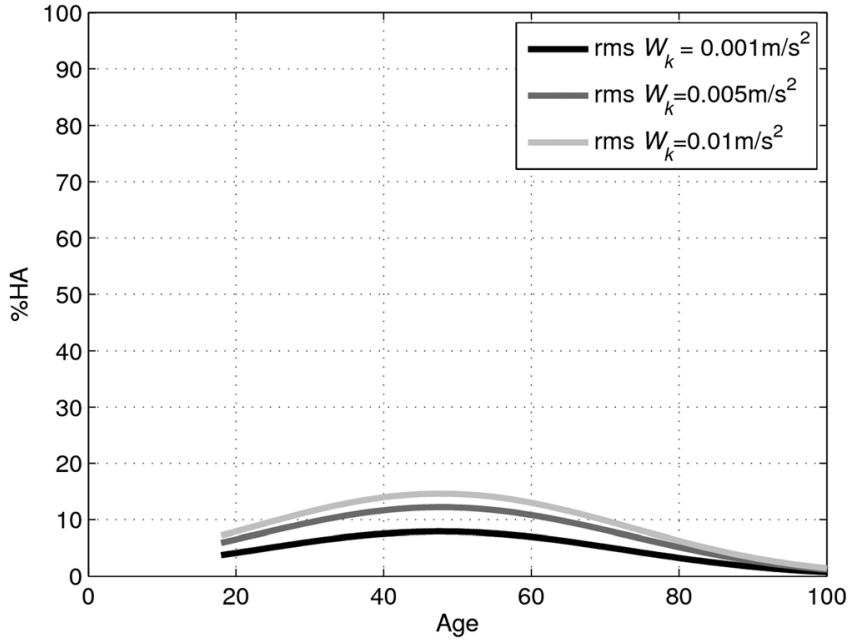

FIG. 7. Exposure-response relationship showing the proportion of people reporting high annoyance $(\% \mathrm{HA})$ as a function of age and vibration exposure.

One possible explanation is the routing in the questionnaire. Those who did not feel vibration from any source were routed away from the sensitivity question and therefore were assumed to be non-sensitive. Another reason that could explain the lack of significant improvement is the wording of the questions. Some of the subjects reported having difficulties or being confused by the vibration sensitivity question. Whereas sensitivity to noise is perhaps a fairly understandable term, the meaning of sensitivity to vibration is perhaps ambiguous. Furthermore, these findings suggest that vibration sensitivity is not linked to somatic components (Heinonen-Guzejev, 2008) or to some psychological attitudes, such as nervousness and introversion, that have been shown to be associated with self-reported noise sensitivity (Moch-Sibony, 1980). As a result, self-reported noise sensitivity could have a greater influence on the vibration annoyance response than the self-reported vibration sensitivity.

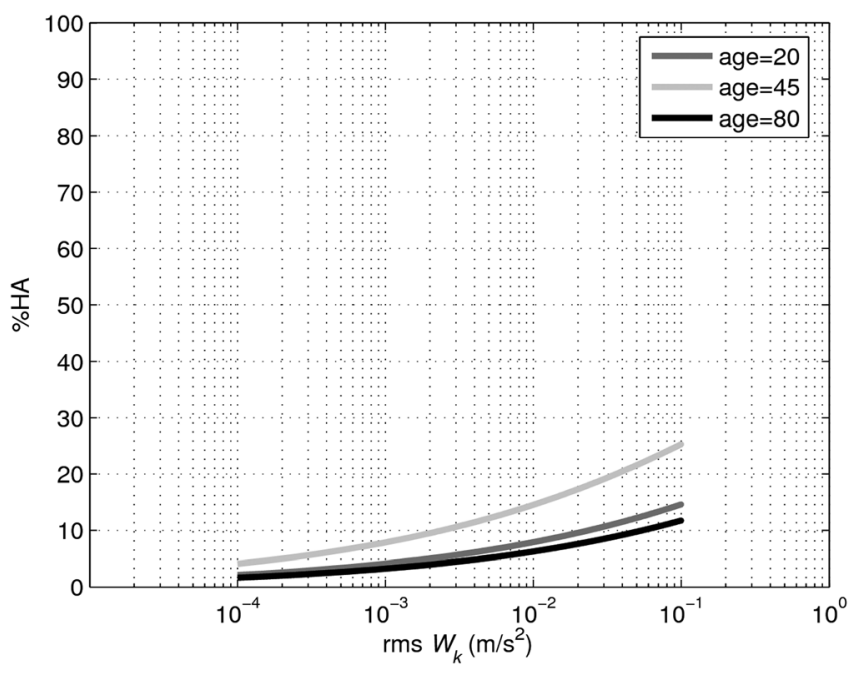

FIG. 8. Exposure-response relationships showing the proportion of people reporting highly annoyed (\% $\mathrm{HA})$ as a function of vibration exposure for three different ages $(20,45$, and $80 \mathrm{yr})$. 
The investigation of concern of property damage showed that as vibration exposure increases, the proportion of respondents expressing concern about damage to their property increases. Moreover, it was found that concern of property damage partially mediates the effect of vibration exposure on self-reported vibration annoyance. There was a statistically significant indirect effect of vibration exposure on self-reported vibration annoyance through concern of property damage. These results might suggest that people highly annoyed by vibrations are also highly concerned. However, the effect of concern of damage to the property on annoyance is perhaps overestimated due to the routing in the questionnaire. People who did not feel vibration from any source were routed away from the "concern of property damage" question and therefore were assumed not to be concerned. Miedema and Vos (1999) found a small influence of fear due to railway on noise annoyance reactions. Vibration is one of the problems associated with railways, and therefore, concern or fear due to railway vibration might have a greater impact on annoyance than fear due to railway noise since vibration can be seen as a property damaging factor.

Ownership appeared to be correlated significantly with concern of property damage but not with vibration annoyance. These findings might explain the inconclusive results obtained in past noise studies with regard to the influence of ownership on noise annoyance (Fields, 1993; Miedema and Vos, 1999). Ownership may be a factor influencing the response when the source induces not only noise but also vibration since concern of property damage is a specific reaction due to vibration from the source.

People's expectations of future vibration levels were found to strongly influence their annoyance response. At the same vibration level, three times more people are expected to be highly annoyed by vibration from railways if they think that vibration levels will get worse than if they think that they will get better or remain the same.

These results suggest that attitudinal factors such as residents' expectations of future exposure, or the belief that railway vibration is damaging their property, have a major influence on top of the vibration exposure levels. Generally, reducing physical levels of exposure is costly; however, these findings provide evidence that knowledge and understanding of attitudinal factors can potentially be a way to reduce or avoid adverse reactions in a more cost-effective way than reducing only exposure levels. The use of attitudinal factors might be a complement to reducing exposure levels. Measures could be adopted to "positivise" people's attitudes toward railway traffic such as engaging with communities to create community acceptance and information sharing. For example, residents could be informed that very low vibration levels are not likely to cause damage to their property, and the railway could be advertised as a modern and quiet means of transport.

From the situational variables explored, type of residential area was found to have an important effect on annoyance, with people being more likely to be highly annoyed if the property was located in a rural area (small town, village, or countryside) than if the property was located in an urban area (city or large town). This result supports noise studies that found relatively high annoyance judgments in quieter areas compared to noisy urban areas (Lercher and Kofler, 1996) but disagrees with others that showed that a quieter neighborhood decreases annoyance (Klæboe et al., 2006). However, the influence of the degree of urbanization on vibration annoyance could also have an attitudinal origin based on people's expectations. For instance, Lercher and Kofler (1996) suggest that the differences in noise annoyance between rural and urban areas is due to differences in attitudes, development schemes, behavior setting as well as background noise exposure. Noise research has shown that there is a greater expectation for peace and quiet in rural areas (International Organization for Standardization, 2003b). Likewise, vibration annoyance could be influenced by the attitudes associated with the type of residential area.

Other factors that showed little but significant influence were visibility of the railway and number of hours spent at home on a week day. Regarding the visibility of the railway, some visual shielding such as vegetation could be explored to reduce annoyance. The number of hours spent at home showed an opposite trend to previous noise studies which found that the greater the time spent at home, the greater the annoyance (Nivison and Endersen, 1993; Paunovic et al., 2009). That could be due to several reasons. One could be that habituation to vibration is different than habituation to noise. Another reason could be that people spending fewer hours at home are working and when they arrive home they desire more peace and quiet in their residential environment. Environmental noise tends to decrease during night-time while railway vibration could be even higher during night periods in areas where freight routes are operating. Moreover, night-time annoyance compared to daytime annoyance due to railway vibration is greater than for environmental noise (Peris et al., 2012).

From the demographic factors only age was found to have an impact on annoyance in the form of an inverted U-shaped relationship where the annoyance was higher for middle aged people. This result is in line with previous noise studies (Van Gerven et al., 2009). People in the middle age range may be more annoyed because they tend to own the property or due to higher work load and therefore more stress. Furthermore, this is also linked with people's time spent at home: People in the middle age group which show highest annoyance also spend less time at home.

Despite the influence of attitudinal, situational and demographic factors found, it has to be kept in mind that in the real environment we can find interaction effects between many variables and usually we will not observe the effect of just one factor purely. A nested model showing the interaction effects between attitudinal, situational and demographic factors is presented in Peris (2012) as well as a summary table showing the strength of the factors affecting vibration annoyance. Moreover, there may be external variables that influence vibration annoyance which are not accounted for in the study design. If these external variables do correlate with the predictors, then the conclusions drawn from the model could become unreliable. 


\section{CONCLUSIONS}

The range of effects of several attitudinal, situational, and demographic variables on the human response to vibration from railways in residential environments were investigated and evaluated.

Of the factors studied it was found that exposureresponse relationships between annoyance scores and vibration exposure were strongly influenced by two attitudinal factors. These were concern of property damage and future expectations of the vibration levels. Concern of property damage appeared to mediate the relationship between annoyance and vibration exposure and results suggest that people highly concerned are more likely to report high annoyance than people who are not concerned at all. Moreover, concern is more likely when the property is owned than when it is rented.

Type of residential area was found to have an important effect on annoyance, with people being more likely to be highly annoyed if the property is located in a rural area such as a small town, a village or the countryside than if the property is located in an urban area such as a city or a large town. Other factors that showed a small but significant influence were visibility of the railway and number of hours spent at home on a week day. From the demographic factors only age was found to have an impact on annoyance in the form of an inverted U-shaped relationship where the annoyance is higher for people in the middle range.

These findings show evidence that knowledge and understanding of these attitudinal factors might lead to a more effective reduction of adverse reactions than could be achieved by reducing exposure levels. The management of vibration impacts in this way is likely to be more costeffective. Thus, in order to create and maintain railway capacity, vibration abatement solutions may not be enough as they will only reduce the environmental impact but not the total human impact. Action plans may be better accompanied by key procedures such as education, communication and information that can be designed based on the results of this paper. Further research is needed to test which of those would be the most effective to engage with communities and to create greater community tolerance of vibration.

The results also indicate that, as well as for noise, selfreported vibration annoyance is governed to large extent by attitudinal factors. However, attitudinal factors influencing railway vibration annoyance differ slightly from those influencing noise reactions.

These investigations are intended to give researchers, planners, local authorities, architects and environmental practitioners a better understanding of people's reactions to vibration from railways. The findings may be useful for the development and implementation of guidance and regulations as well as for making assessments of annoyance caused by railway vibration.

\section{ACKNOWLEDGMENTS}

This research was funded by the Department for Environment, Food and Rural Affairs (Defra) UK.
Bangjun, Z., Lili, S., and Guoqing, D. (2003). "The influence of the visibility of the source on the subjective annoyance due to its noise," Appl. Acoust. 64, 1205-1215.

Baron, R. M., and Kenny, D. A. (1986). "The moderator-mediator variable distinction in social psychological research: Conceptual, strategic, and statistical considerations,” J. Personal. Soc. Psychol. 51, 1173-1182.

Bradley, J. S., and Jonah, H. (1979). "The effects of site selected variables on human response to traffic noise, part I: Type of housing by traffic noise level," J. Sound Vib. 66, 589-604.

Brink, M., and Wunderli, J.-M. (2010). "A field study of the exposureannoyance relationship of military shooting noise," J. Acoust. Soc. Am. 127, 2301-2311.

Cohen, S. (1978). "Environmental load and the allocation of attention," in Advances in Environmental Psychology: Vol. 1. The Urban Environment, edited by A. Baum, J. E. Singer, and S. Valins (Lawrence Erlbaum Assoc., Hillsdale, NJ), pp. 1-29.

Condie, J., Whittle, N., Brown, P., and Waddington, D. (2009). "The development of a social survey questionnaire to investigate human response to vibration in residential environments," in Proceedings of Euronoise (Edinburgh, Scotland), Vol. 23, pp. 971-981.

Fidell, S., Mestre, V., Schomer, P. Berry, B., Gjestland, T., Vallet, M., and Reid, T. (2011). "A first-principles model for estimating the prevalence of annoyance with aircraft noise exposure," J. Acoust. Soc. Am. 130(2), 791-806.

Field, A. (2009). Discovering Statistics Using SPSS, edited by D. B. Wright (SAGE Publications, London), Chap. 7, pp. 223-224.

Fields, J. (1979). "Railway noise and vibration annoyance in residential areas," J. Sound Vib. 66(3), 445-458.

Fields, J. M. (1993). "Effect of personal and situational variables on noise annoyance in residential areas,” J. Acoust. Soc. Am. 93, 2753-2763.

Fields, J. M. (1998). "Reactions to environmental noise in an ambient noise context in residential areas," J. Acoust. Soc. Am. 104(4), 2245-2260.

Fields, J. M., de Jong, R. G., Gjestland, T., Flindell, I. H., Job, R. F. S., Kurra, S., Lercher, P., Vallet, M., Guski, R., Felscher-Suhr, U., and Schuemer, R. (2001). "Standardized general-purpose noise reaction questions for community noise surveys: Research and a recommendation," J. Sound Vib. 242(4), 641-679.

Fields, J. M., and Walker, J. (1982). "The response to railway noise in residential areas in Great Britain,” J. Sound Vib. 85(2), 177-255.

Guski, R. (1999). "Personal and social variables as co-determinants of noise annoyance," J. Noise Health 3, 45-56.

Guski, R. (2001). "Community response to environmental noise," in Environmental Urban Noise, edited by A. Garcia (WIT Press, Southampton), pp. 111-148.

Hatfield, J., and Job, R. F. S. (1998). "Evidence of optimism bias regarding the health effects of exposure to noise," in Proceedings of the 7th International Congress on Noise as a Public Health Problem 98, Sydney, Australia, pp. 251-254.

Heinonen-Guzejev, M. (2008). "Noise sensitivity-Medical, psychological and genetic aspects," Ph.D. dissertation, Dep. of Public Health, Univ. of Helsinki, Finland.

Howarth, H. V. C. (1989). "Annoyance caused by railway vibration and noise in buildings," Ph.D. dissertation, Human Factors Research Unit, Univ. of Southampton, Southampton, UK.

International Organization for Standardization (1997). ISO 2631-1. Mechanical Vibration and Shock-Evaluation of Human Exposure to Whole-Body Vibration-Part 1: General Requirements (International Organization for Standardization Geneva, Switzerland).

International Organization for Standardization (2003a). ISO/TS 15666. Acoustics - Assessment of Noise Annoyance by Means of Social and Socio-Acoustic Surveys (International Organization for Standardization, Geneva, Switzerland). International Organization for Standardization (2003b). ISO 1996-1. Acoustics - Description, Measurement and Assessment of Environmental Noise - Part 1: Basic Quantities and Assessment Procedures (International Organization for Standardization, Geneva, Switzerland).

Job, R. F. S. (1988). "Community response to noise: A review of factors influencing the relationship between noise exposure and reaction," J. Acoust. Soc. Am. 83, 991-1001.

Job, R. F. S. (1999). "Noise sensitivity as a factor influencing human reactions to noise," J. Noise Health 3, 57-68.

Klæboe, R., and Fyhri, A. (1999). "People's reactions to vibrations in dwellings from road and rail (summary in English)," Report 443 (Institute of Transport Economic, Oslo, Norway).

Klæboe, R., Engelien, E., and Steinnes, M. (2006). "Context sensitive noise impact mapping," Appl. Acoust. 67(7), 620-642. 
Klæboe, R., Kolbenstvedt, M., Lercher, P., and Solberg, S. (1998). "Changes in noise reactions-Evidence for an area effect?," in Proceedings of Internoise 1998 (Christchurch, New Zealand), pp. 16-18.

Klæboe, R., Turunen-Rise, I. H., Hårvik, L., and Madshus, C. (2003). "Vibration in dwellings from road and rail traffic-Part II: Exposureeffect relationships based on ordinal logit and logistic regression models," Appl. Acoust. 64(1), 89-109.

Lercher, P., and Koffler, W. W. (1996). "Behavioral and health responses associated with road traffic noise exposure along alpine through-traffic routes," Sci. Total Environ. 189/190, 85-89.

Miedema, H., and Vos, H. (1998). "Exposure-response relationships for transportation noise," J. Acoust. Soc. Am. 104(6), 3432-3445.

Miedema, H., and Vos, H. (1999). "Demographic and attitudinal factors that modify annoyance from transportation noise," J. Acoust. Soc. Am. 105, 3336-3344.

Miedema, H. M. E., and Oudshoorn, C. G. M. (2001). "Annoyance from transportation noise: Relationships with exposure metrics DNL and DENL and their confidence intervals," Environ. Health Perspect. 109(4), 409-416.

Moch-Sibony, A. (1980). "Les effets du bruit sur l'homme" ("The effects of noise on man"), Rev. Acoust. 55, 251-257.

Nelson, P. (1987). Transportation Noise. Reference Book (Butterworths University Press, Cambridge, UK), Chap. 3.

Nivison, M. E., and Endresen, I. M. (1993). "An analysis of relationships among environmental noise, annoyance and sensitivity to noise, and the consequences for health and sleep," J. Behav. Med. 16(3), 257-276.

Obermeyer, P. (1983). "Interdisziplinäre Feldstudie II über die Besonderheiten des Schienenverkehrslärm gegenüber dem StraBenverkehrslärm; 2 Bände" ("Interdisciplinary field study about the characteristics of railway traffic noise compared to road traffic noise; volume 2"), München Forschungs-Nr. 7008/80 (Bundesministerium, Bonn, Germany).

Öhrström, E., and Skånberg, A. B. (1996). "A field survey on effects of exposure to noise and vibration from railway traffic, part I: Annoyance and activity disturbance effects," J. Sound Vibr. 193(1), 39-47.

Paunovic, K., Jakovljevic, B., and Belojevic, G. (2009). "Predictors of noise annoyance in noisy and quiet urban streets," Sci. Total Environ. 407(12), 3707-3711.

Pedersen, E., and Larsman, P. (2008). "The impact of visual factors on noise annoyance among people living in the vicinity of wind turbines," J. Environ. Psychol. 28, 379-839.
Peris, E. (2012), "Human response to railway vibration in residential environments: Exposure-response relationships and modifying factors," Ph.D. thesis, The Universiy of Salord, UK, Chap. 5.

Peris, E., Woodcock, J., Sica, G., Moorhouse, A., and Waddington, D. (2012). "Annoyance due to railway vibration at different times of the day," J. Acoust. Soc. Am. 131(2), 191-196.

Schomer, P., Mestre, V., Fidell, S., Berry, B., Gjestland, T., Vallet, M., and Reid, T. (2012). "Role of community tolerance level (CTL) in predicting the prevalence of the annoyance of road and rail noise," J. Acoust. Soc. Am. 131(4), 2772-2786.

Schultz, T. J. (1978). "Synthesis of social surveys on noise annoyance," J. Acoust. Soc. Am. 64(2), 377-405.

Sobel, M. E. (1986). "Some new results on indirect effects and their standard errors in covariance structure models," Sociol. Methodol. 16, 159-186.

Stiebel, D. (2011). "Protocol for free field measurements of mitigation effects in the project RIVAS for WP 2, 3,4, 5," Report WP1.2 No: SCP0-GA-2010265754). FP7 framework, Brussels, http://www.rivas-project.eu/fileadmin/ documents/rivas_db_wp1_d1_2_v04_measuring_protocol.pdf (Last viewed 1 July 2013).

Vallet, M. (1996). "Annoyance after changes in airport noise environment," in Proceedings InterNoise 96 (Liverpool, England), Vol. 5, pp. 2395-2400.

Van Gerven, P. W. M., Vos, H., Van Boxtel, M. P. J., Janssen, S. A., and Miedema, H. M. E. (2009). "Annoyance from environmental noise across the lifespan," J. Acoust. Soc. Am. 126, 187-194.

Waddington, D. C., Woodcock, J., Peris, E., Condie, J., Sica, G., Moorhouse, A. T., and Steele, A. (2014). "Human response to vibration in residential environments," J. Acoust. Soc. Am. 135, 182-193.

Woodcock, J., Peris, E., Condie, J., Sica, G., Koziel, K., Evans, T., Moorhouse, A., Steele, A., and Waddington, D. (2011). "Human response to vibration in residential environments (NANR209), Determination of exposure-response relationships," Technical Report 6 (Defra, London).

Yonekawa, Y. (1977). "Evaluation of bullet train vibration for residents near railways," Indust. Health $\mathbf{1 5}, 23-32$.

Zapfe, J. A., Saurenman, H., and Fidell, S. (2009). "Ground-borne noise and vibration in buildings caused by rail transit," Contractor's Final Report for TCRP Project D-12 - Ground-Borne Noise and Vibration in Buildings Caused by Rail Transit, Transportation Research Board, Washington, DC. 